\title{
Garments Worker's Job Stress and Mental Health
}

\author{
Biplob Kumar Dey ${ }^{1 *}$, Abdur Rahman $^{2}$, Mst. Sabiha Sultana ${ }^{3}$, Sahila Sadaf ${ }^{4}$
}

\section{ABSTRACT}

The present study attempted an empirical investigation to explore the job stress and mental health of garment workers as a function of gender and salary. A total of 120 respondents constituted the sample of the study were selected purposively of Chittagong district Bangladesh. Among them 60 workers were male (20 were salary ranges of 4000-8000 F, 20 were salary ranges of 8100-12000 $\mathrm{F}$ and 20 were salary ranges of above $12000 \mathrm{~F}$ ) and 60 workers were female (20 were salary ranges of 4000-8000 F, 20 were salary ranges of 8100-12000 F and 20 were salary ranges of above 12000 -). An adapted Bengali version (Rahman and Sorcar, 1990) of 'Job Stress' scale and Bengali version (Sorcar and Rahman, 1989) of “Mental Health” scale were used. Data were analyzed by mean, standard deviation, Pearson Product Moment Correlation and two-way analysis of variance (ANOVA). The findings of the present study showed that female workers had significantly more job stress $(F=72.07, d f=1, p<.00)$ than male workers and lowest salary ranges workers had significantly more job stress $(F=20.78, d f=2, p<.00)$ than highest salary ranges workers. No significant interaction effect found between gender and salary according to job stress. On the other hand, gender had no significant effect on mental health and highest salary ranges workers had significantly more mental health $(F=5.71, d f=2, p<.00)$ than lowest salary ranges workers. No significant interaction effect found between gender and salary according to mental health. Results also showed that job stress was negatively correlated $(\mathrm{r}=$ $.35, p<.01$ ) with mental health.

Keywords: Garment Workers, Job Stress, Mental Health.

Nobody can deny that jobs and careers are paramount part and parcel of our lives. A person who works in garments is called garment workers. Someone whose occupation is making or repairing fur garments products is called garment workers. Someone says that the persons who makes or mends dresses in the factory or garment industry is called garment workers. In another sense,

\footnotetext{
${ }^{1}$ Assistant Professor, Department of Psychology, University of Chittagong, Bangladesh.

${ }^{2}$ Assistant Professor, Department of Psychology, University of Chittagong, Bangladesh.

${ }^{3}$ Lecturer, Department of Psychology, University of Chittagong, Bangladesh.

${ }^{4}$ Ms Students, Department of Psychology, University of Chittagong, Bangladesh.

*Responding Author

(C) 2016 I B Dey, A Rahman, S Sultana, S sadaf; licensee IJIP. This is an Open Access Research distributed under the terms of the Creative Commons Attribution License (http://creativecommons.org/licenses/by/2.0), which permits unrestricted use, distribution, and reproduction in any Medium, provided the original work is properly cited.
} 


\section{Garments Worker's Job Stress and Mental Health}

someone who does work as sewing or embroidery with a needle someone who sells men's clothes a garment maker who performs the finishing steps person whose occupation is making and altering garments someone who does work as sewing or embroidery with a needle. Along with providing a source of income, they help us fulfill our personal aims, build social networks and serve our professions or communities.

Job stress can be defined as the harmful physical and emotional responses that occur when the requirements of the job do not match the capabilities, resources, or needs of the worker. Job stress can lead to poor health and even injury. Job stress is stress involving work. According to the current

World Health Organization's (WHO) definition, occupational or work-related stress is the response people may have when presented with work demands and pressures that are not matched to their knowledge and abilities and which challenge their ability to cope. Warr and Payne (1983) showed that stress more often comes from how we respond to stressful events than from the events themselves. Some people feel less stressed because they see themselves as able to cope. People who view themselves as in control generally feel less stress.

Mental health includes our emotional, psychological, and social well-being. It affects how we think, feel, and act. It also helps determine how we handle stress, relate to others, and make choices. Mental health is zenith important at every phases of life, from childhood and adolescence through adulthood. Mental health is defined as a state of well-being in which every individual realizes his or her own potential, can accommodate with the normal stresses of life, can work productively and fruitfully, and is able to make a contribution to her or his community. Mental health can be described as the ability to respond to many varied experiences of life with flexibility and a sense of purpose. It is the state of balance between the individual and the surrounding world. According to World Health Organization (WHO) mental health includes; subjective well-being, perceived self-efficacy, autonomy, competence, intergenerational dependence, and self-actualization of one's intellectual and emotional potential, among others.

Wright et al., (1994) studied aspects of psychological work environment and health among male and female white-collar and blue-collar workers in a big Swedish industry. They reported that blue collar workers had more complaints about their physical and mental symptoms and less pleasure in work, when compared to white collar workers.

Occupational stress among factory workers has also been studied in developing countries. Rahman (1989) conducted an empirical study on male factory workers in Bangladesh. He found that workers in the high stress group were dissatisfied with their work and reported poorer mental health than the workers of the low stress group. 


\section{Garments Worker's Job Stress and Mental Health}

Shankar and Famuyiwa (1991) examined Stress among factory workers in a developing country. And they concluded that job stress had significant impact on the mental health.

There has been quite a lot of research done within the work force in Taiwan. Taiwanese industrial workers placed great emphasis on social relationships at work (Cheng, 1980). Even the inability to maintain a harmonious relationship between co-workers has been rated as a major factor for work-related stress, burnout, and resignation (e.g., Huang, 1986; Kuo, 1989,1990). As far as demographics are concerned, male workers have higher job satisfaction and job commitment than female workers (Su and Huang, 1992). Married workers reported higher job satisfaction and job commitment than single workers (e. g., Chen and Huang, 1982; Huang, 1984; Su and Huang, 1992). Single workers even reported more job related stress than married workers (Hsu and Chen 1981). Older employees with longer working experience tend to report more job satisfaction and job commitment (e. g., Huang, 1986; Su and Huang, 1992; Chen and Huang, 1982).

Siu and Donald (1996) studied workers stress among workers from eight occupational groups in Hong Kong. They found that there was a statistically significant relationship between workers perceived stress, health complaints and job dissatisfaction. They also found that workers who were dissatisfied with the physical condition perceived a higher level of work stress, and exhibited more health complaints. But nearly all of these studies obtained data from white collar and professional groups.

Other studies have shown that the timing of work is also linked to adult mental health. Shift work, extended working hours and night work disrupt circadian patterns leading to anxiety, depression, mental distress and poor family relationships (Caruso, 2006; Virtanen et al., 2010). Nigam et al., (2007) conducted a study on safety and health in chemical industry. The study addressed the present global industrial scenario, for any industry to be successful, it is essential to inculcate safety culture, health consciousness and environmental awareness in every employee of the organization.

Paul- Majumder (2003) conducted a study on the physical and mental health status of garment workers and how problem affect labor productivity, competitiveness of the garment industry in the world market and the working life of the workers, particularly of female workers. It showed that various illnesses and diseases were widespread among the garment workers. A large number of workers were found to continue their work even they were suffering from various diseases and illness. Though the garment workers were very young they suffered from anemia, female diseases, dysentery, etc. Moreover, the competitiveness of the garment industry in the world market was seriously affected by the ill health of the workers, since ill health decreases the labor productivity to a great extent. Most of the health problems that the garment workers suffered from arose from the occupational hazards including long working hours, absence of leave

(C) The International Journal of Indian Psychology, ISSN 2348-5396 (e)| ISSN: 2349-3429 (p) | 128 


\section{Garments Worker's Job Stress and Mental Health}

facilities, congested and over-crowded working conditions, absence of health facilities and safety measures, absence of staff amenities, lack of safe drinking water etc.

\section{Rationale of the study}

Garment industry is the apex resource and leading sector of foreign currency in Bangladesh. This sector not only improves of our domestic growth but also enhances goodwill of foreign country. It helps us to reduce of our unemployment problems. Unfortunately, our government is indifferent of their development and wages. The garment workers are deprived of their various facilities such as good salary, promotion, provident fund, residence, allowance etc. Their life style is so miserable that they fail to supply their basic needs for their family members. Actually, it is great surprising that mainly our economy stands on their industry, but government and nongovernment institutions are not conscious of their minimum rights. Therefore, there are some selfish owners of garment industry who have a tendency to provide low wages and force to work hard. Their work environment is not supportive for their work. Some problems are existing in garment industry, such as lack of emergency service, lack of hygiene, lack of work space, noise etc which creates them job stress. Continuously suffering from job stress, it impacts on their physical and mental health. So, present research is conducted on garment workers to understand Bangladeshi garment workers have job stress during their work and also how they can get proper mental health which can make their life smoother during work. Most of the studies in this area have been done in western culture, but in Bangladesh there are very few studies. The findings of the study would have some applied values and the study would give new knowledge about job stress and mental health among garment workers. Therefore, this study will help us to provide such information which is very essential for mental health workers, psychologists, sociologists, governments, NGOs and policy makers to take effective steps to facilitate 'garment workers' development.

\section{Objectives of the study}

From the rationale, the main objective of the present study is to find out relation between job stress and mental health among garment workers as a function of gender and salary. Other objective is i) to investigate whether job stress of garment workers varies as a function of gender and salary and ii) to see whether mental health of garment workers varies as a function of gender and salary.

\section{METERIALS AND METHODS}

\section{Participants}

The sample of the present study constituted of 120 garment workers. Among the 120 garment workers 60 were male workers. 60 male workers were taken in which (20 were of salary ranges of 4000 - to 8000 - per month, 20 were of salary ranges of 8100 - to 12000 - per month and 20 were of salary ranges of above tk. 12000 - per month). Among the 120 garment workers 60 were female workers. 60 female workers were taken in which (20 were of salary ranges of $4000+$ to 


\section{Garments Worker's Job Stress and Mental Health}

8000 - per month, 20 were of salary ranges of 8100 - to 12000 - per month and 20 were of salary ranges of above tk. 12000 - per month). The sample of both groups was purposively selected from various areas in Chittagong district. These workers belong to different areas (Sholoshahar, 2no.gate, Baijid Bostami, Lalkhanbazar, Motijhorna, Agrabad, EPZ). Maximum workers socio-economic status was lower class and they were not so much educated.

\section{Measuring Instruments}

In the present research the following two questionnaire were used such as

Job Stress Scale: Job stress was measured by using the job stress index developed by Srivastava and Singh (1981) which consisted of 46 items covering 12 dimensions of job stress. These are: role overload, role ambiguity, role conflict, unreasonable group and political pressures, responsibility for persons, under participation, powerlessness, poor pear-relations, intrinsic impoverishment, low status, strenuous working conditions, and unprofitability. Out of 46 items, 28 are true-keyed items and the remaining 18 items are false-keyed items. The reliability of the scale was tested by split-half method. It was 0.94 and, found to be highly significant. For the present study, a Bengali version adapted by Rahman and Sorcar (1990) of the index was used which was found to have high inter judge agreement. The responses were given weights of 1,2,3,4 \& 5 respectively for strongly disagreeing to strongly agree.

Mental Health Scale: Mental health of the respondents measured by the translated and adapted version (Sorcar and Rahman, 1989) of the original GHQ (General Health Questionnaire) was developed by Goldberg (1972). It is a self administered screening test designed for detecting people with diagnosable psychiatric disorders. The GHQ - 12 is concerned with two phenomena: the inability to carry out one's normal health functions and the new phenomena of a distressing nature. Each item of the scale consists of question asking whether the respondent has recently experienced a particular symptom of behavior rated on 4-pointscale. Responses were given weights of $0,1,2 \& 3$ respectively. Among the 12 items, 6 were positive and 6 were negative. Positive items were scored in 4-points from 3-0 and negative items in the reverse order from 0-3, total score of the scale range from 0-36 with higher score indicating better mental health. The reliability of the Bengali version of the GHQ-12 was measured by parallel form method and was found to be quite satisfactory $(r=0.69)$.

\section{Design}

A cross-sectional survey research design was followed for conducting present study.

\section{Procedure}

At first we were going to the residence of garment workers of Chittagong district in Bangladesh. Then they were requested to co-operate with us for conducting the research. After convincing them to conduct the research, the purposively selected workers were then supplied with a set of questionnaires. The respondents were requested to read each statement \& expressed their feelings by putting on tick mark $(\sqrt{ })$ on the appropriate point. Respondents fulfilled their 


\section{Garments Worker's Job Stress and Mental Health}

questionnaires but there was no time limit condition. Respondents were assured that it was purely an academic research and that their personal information would be kept secret. After the questionnaires were filled in by the respondents, they were thanked for their co-operation.

\section{RESULTS AND DISCUSSION}

The data were analyzed by using mean, standard deviation, Pearson Product Moment Correlation and two-way analysis of variance (ANOVA). All statistical analyses were carried out using the statistical program SPSS version 16.0 for window.

Table 1 indicates that mean job stress score of male workers was $137.40(S D=8.97)$ and female workers was $150.23(S D=10.35)$ and mean job stress score of workers salary ranges of 4000 8000 - was $146.35(S D=11.27)$, salary ranges of $8100-12000$ - was $148.10(S D=11.28)$ and salary ranges of above 12000 - was $137.00(S D=9.12)$.

Table 1: Descriptive statistics of job stress score according to gender and salary.

\begin{tabular}{|lcccc|}
\hline \multicolumn{4}{c|}{ Salary } \\
\hline Gender & $4000-8000+$ & $8100-12000+$ & above $12000+$ & Total \\
& & & & \\
Male & $M=137.50$ & $M=143.60$ & $M=131.10$ & $M=137.40$ \\
& $S D=6.86$ & $S D=7.00$ & $S D=8.44$ & $S D=8.97$ \\
& & & & \\
Female & $M=155.20$ & $M=152.60$ & $M=142.90$ & $M=150.23$ \\
& $S D=6.96$ & $S D=13.00$ & $S D=5.11$ & $S D=10.35$ \\
& & & & \\
Total & $M=146.35$ & $M=148.10$ & $M=137.00$ & \\
& $S D=11.27$ & $S D=11.28$ & $S D=9.12$ & \\
\hline
\end{tabular}

To determine whether the differences observed between the means in Table 1 were statistically significant, two-way analysis of variance (ANOVA) was computed. Table 2 shows that gender had significant effect on workers stress $(F=72.07, d f=1, p<.00)$ and salary had significant effect on workers job stress $(F=20.78, d f=2, p<.00)$. Female workers had more job stress than male workers and lower salary ranges workers had more stress than higher salary ranges workers. The result also shows no significant interaction effect between gender and salary. 


\section{Garments Worker's Job Stress and Mental Health}

Table 2: Summary of the analysis of variance of job stress according to gender and salary.

\begin{tabular}{|llllll|}
\hline Source of Variance & $\boldsymbol{d} \boldsymbol{f}$ & $\boldsymbol{S S}$ & MS & $\boldsymbol{F}$ & Sig. (p-value) \\
\hline Gender & 1 & 4940.83 & 4940.83 & 72.07 & .00 \\
Salary & 2 & 2849.27 & 1424.63 & 20.78 & .00 \\
Gender* Salary & 2 & 394.47 & 197.23 & 2.88 & .06 \\
Error & 114 & 7815.40 & 68.56 & & \\
Total & 120 & 2497988.00 & & & \\
\hline
\end{tabular}

Table 3 shows that mean mental health score of male workers was $10.70(S D=3.09)$ and female workers was $9.80(S D=3.59)$ and mean mental health score of workers salary ranges of 4000 8000 was $8.90(S D=2.81)$, salary ranges of $8100-12000$ - was $10.60(S D=3.80)$ and salary ranges of above 12000 - was $11.25(S D=3.05)$.

Table 3: Descriptive statistics of mental health score according to gender and salary.

\begin{tabular}{|lcccc|c|}
\hline \multicolumn{5}{|c|}{ Salary } \\
\hline Gender & $4000-8000-$ & $8100-12000-$ & above $12000-$ & Total \\
Male & $M=9.20$ & $M=10.50$ & $M=12.40$ & $M=10.70$ \\
& $S D=2.59$ & $S D=3.53$ & $S D=2.26$ & $S D=3.09$ \\
Female & $M=8.60$ & $M=10.70$ & $M=10.10$ & $M=9.80$ \\
& $S D=3.05$ & $S D=4.14$ & $S D=3.34$ & $S D=3.59$ \\
Total & $M=8.90$ & $M=10.60$ & $M=11.25$ & \\
& $S D=2.81$ & $S D=3.80$ & $S D=3.05$ & \\
\hline
\end{tabular}

To investigate whether the differences observed between the means in Table 3 were statistically significant, two-way analysis of variance (ANOVA) was computed. Table 4 shows that gender has no significant effect on workers mental health $(F=2.36, d f=2, p<.13)$ and salary has significant effect on mental health $(F=5.71, d f=2, p<.00)$. Male workers had higher mental health than female workers. And higher salary level workers had high mental health than lower salary level workers. The result also shows no significant interaction effect between gender and salary.

(C) The International Journal of Indian Psychology, ISSN 2348-5396 (e)| ISSN: 2349-3429 (p) | 132 


\section{Garments Worker's Job Stress and Mental Health}

Table 4: Summary of the analysis of variance of mental health according to gender and salary.

\begin{tabular}{|lclccl|}
\hline Source of Variable & $\boldsymbol{d} \boldsymbol{f}$ & \multicolumn{1}{c}{$\boldsymbol{S S}$} & $\boldsymbol{M S}$ & $\boldsymbol{F}$ & Sig. (p-value) \\
\hline Gender & 1 & 24.30 & 24.30 & 2.36 & .13 \\
Salary & 2 & 117.80 & 58.90 & 5.71 & .00 \\
Gender * Salary & 2 & 32.60 & 16.30 & 1.58 & .21 \\
Error & 114 & 1175.80 & 10.31 & & \\
Total & 120 & 13958.00 & & & \\
& & & & & \\
\hline
\end{tabular}

Finally, to find out whether there is any relation between job stress and mental health of gender (male and female) and different salary ranges (4000-8000 - 8100-12000 \& \& above 12000 -) workers. Pearson Product Moment Correlation was conducted. Negative correlation $(r=-.35)$ was found between job stress and mental health in workers with an alpha level of $p<.01$. That means the increase of job stress, mental health decrease.

The present study has focused on to find out relation between job stress and mental health among garment workers as a function of gender and salary. The first objective of the present study was to investigate whether job stress of garment workers varies as a function of gender and salary. The result indicates that job stress score of female was higher than male workers. The result also indicates that job stress score of salary ranges 4000-8000 - and 8100-12000 + was higher than salary ranges above 12000 - of workers. The mean score indicate that workers job stress score of female $(M=150.23, S D=10.35)$ was higher than the score of male $(M=137.40, S D=8.97)$. Garment workers are doing so many works in factories. They have so much pressure during their work. Their salary also very low compared to their work. They work so hard from early morning to night. But they can't get enough money for their work. So, they feel little enthusiasm for doing job. They feel frustrated in carrying out responsibilities at work. Their quality of work is less day by day. And they feel negative or depressed about their job. Both male and female workers can't give much time to their families. Especially women workers who have to manage their household chores beside their job can't give enough time to their families and friends. They can't give proper attention to their children. They feel physically, emotionally or spiritually depleted. They face some difficulties about decision making and having difficulties in concentrate their maximum work. They feel dissatisfaction whatever they do their everyday life. These issues facilitate stress among workers. Rahman (1989) conducted an empirical study on male factory workers in Bangladesh. He found that workers in the high stress group were dissatisfied with their work. Because of job stress they can't do any work properly. They feel frustrated in carrying out responsibilities at work. Male workers have higher job satisfaction and job commitment than female workers (Su \& Huang 1992). Male are stronger than women. They can do more work than women. Women have less potentiality to manage both job and family. So female workers have more stress than men workers. 


\section{Garments Worker's Job Stress and Mental Health}

On the other hand, mean score indicate that workers job stress score of salary ranges 4000$8000+(M=146.35, S D=11.27)$ \& salary ranges $8100-12000+(M=148.10, S D=11.28)$ was higher than score of above $12000+(M=137.00, S D=9.12)$. The workers whom salary was less and medium had more job stress than highest salary paid workers. Because lowest salary paid workers work so hard \& their work was so risky. They work from early morning to night. But they can't get sufficient money what they actually deserve. With this little amount they can't fulfill their family's daily needs. The workers who have much money can give their family a better lifestyle than the workers who have lowest salary. So, that lowest salary paid workers have more job stress than highest salary paid workers. Rogers (2010) in his writing mentioned that Bangladeshi garment workers are the lowest paid garment workers in the world. Although their minimum wage was supposed to have risen to about $\$ 40$ a month in November 2010, many garment factory owners are still paying the old minimum wage of $\$ 24$ a month. Their lowest salary leads to job stress. In our study we found that the workers whose salary ranges medium had more job stress than lowest salary paid workers and highest salary paid workers. Because the work they had was more difficult than lowest and highest salary ranges workers. But their salary was not enough for their work. So under the pressure of so many works they had job stress.

The second objective of the present study was that to see whether mental health of garment workers varies as a function of gender and salary. The result indicates that there was no significant difference in mental health score of male and female. The results also indicate that mental health score of salary ranges above 12000 - was higher than salary ranges 4000-8000 and $8100-12000$ - The mean scores indicate that workers mental health score of male $(M$ $=10.70, S D=3.09)$ and female $(M=9.80, S D=3.59)$ was almost same. Male and female both worked outside of home. Their responsibilities were also same. They had equal value in their family and society. So there was no difference in male and female mental health score.

On the other hand mean score indicate that workers mental health of salary ranges above $12000+$ $(\mathrm{M}=11.25, \mathrm{SD}=3.05)$ was higher than score of salary ranges $4000-8000+(\mathrm{M}=8.90, \mathrm{SD}=2.81)$ and $8100-12000+(\mathrm{M}=10.60, \mathrm{SD}=3.80)$. These findings showed that the workers who have highest salary have higher mental health than the workers who have lowest salary. Highest salary paid workers had good mental health than lowest salary paid workers. Different level of salary can affect mental health. The workers who earn more money can fulfill their needs \& they can give their family and children a better life. But lowest salary paid worker have less money \& they face so many problem in their life. Their living style, socio-economic status, educational qualification is different from highest salary paid workers. They cannot give their children proper education. Most of the women workers whom husbands were not with them have more trouble in their life. They face so many difficulties in their life because of less money. They don't have self control. They emotionally and psychologically deprived. They are unable to balance rationality and emotionality. So their mental health is low. 


\section{Garments Worker's Job Stress and Mental Health}

The final objective of the study was to observe whether there is any relation between job stress and mental health among garment workers as a function of gender and salary. Negative correlation $(\mathrm{r}=-.35)$ was found between job stress and mental health of workers with an alpha level of $\mathrm{p}<.01$. It reveals moderately significant relationship between the job stress and mental health of gender and salary among garment workers. The workers who have higher job stress, their mental health is poorer. And the workers of poorer job stress have higher mental health. That means workers of poor job stress and high mental health can adjust with different circumstances in their life, they can make decisions, they can take care of their families and children without any stress, they can lead their life properly. But the workers of high job stress and poor mental health can’t lead their life properly, can’t express their feelings to others.

The main limitation of the present study was; purposive sampling has narrowed the scope of the present study in terms of generalizing the findings and therefore, the number of the participants was only 120 which were not enough for the generalization for the findings. Further studies should carry out analysis on duration, age, education, family type, specific behavior, social or physical health problems of garment workers.

From the above limitation this study may have important recommendations; workers works in garment factories represent our country to the worldwide. Therefore, garment authorities should give them chance to develop new skills, reward them if workers done their job finely. Workers should take a short break at work if they feel anxious or stressed. They should eat healthy meals, express their feelings to their close ones, spend time with friends and family, should get enough sleep. The findings of present study are helpful for authorities of garment factories to identify what problems are faced by these workers so that they can help them to cope up with their problems through proper counseling and guidance services arrangements.

\section{Acknowledgments}

The author appreciates all those who participated in the study and helped to facilitate the research process.

\section{Conflict of Interests}

The author declared no conflict of interests.

\section{REFERENCES}

Caruso, C. (2006). Possible broad impacts of long work hours. Industrial Health, 44, 531- 536.

Chen, S. R., \& Huang, K. L. (1982). The relationship between personality, needs, work nature and job satisfaction (in Chinese), Management Review, 1(1), 18-38.

Cheng, K. H. (1980). Workers and their job attitudes: Exploratory studies of young Factory workers (in Chinese), Bulletin of the Institute of Ethnology, 26: 1-170.

Goldberg, D. (1972). The detection of Psychiatric Illness by Questionnaire. London: Oxford University Press.

(C) The International Journal of Indian Psychology, ISSN 2348-5396 (e)| ISSN: 2349-3429 (p) | 135 


\section{Garments Worker's Job Stress and Mental Health}

Hsu, M. L., \& Chen, S. C. (1981). An empirical study of employee's job stress (in Chinese), Bulletin of the Institute of ethnology, 51, 63-88.

Huang, K. L. (1984). Employees and job satisfaction in organizational setting; A study in Taiwan (in Chinese). In National Taiwan University (Ed.), Chinese Management Research Seminar (pp. 1-14). Taiwan: Taiwan National University.

Huang, K. L. (1986). Organizational commitment and career commitment among Taiwanese high school teachers (in Chinese), National Chengzhi University Bulletin, 53, 55-84.

Ilyas, Q. S. M. (2002). Bengali version of Mental Health Scale, Unpublished manuscript, department of Psychology, University of Dhaka.

Kuo, S. Y. (1989, 1990). Stress and burnout among Taiwanese teachers [in Chinese], Bulletin of Educational Psychology, 23, 71-98.

Nigam, N. C., Maheshwari, A. K., \& Roa, N. P. (2007). Safety and Health in Chemical Industry. Indian Journal of Fertilizers, 3, (7), 13-20, 23-26.

Paul - majumder, P. (2003). Health Status of the Garment Workers in Bangladesh, Arambagh, Motijheel, Dhaka, Bangladesh at Associates Printing Press.

Rahman, A., \& Sorcar, N. (1990). Occupational Stress, Marital Status and Job Satisfaction of working women. The Dhaka University Studies, 11(1), 55-61.

Rahman, M. (1989). Job stress, satisfaction and mental health of factory workers in Bangladesh, Work and Stress, 3, (2), 155-162.

Rogers, W. (2010). Fire Kills Garment Workers: Workers Protest Low Wages. The working conditions and wages of workers in the Bangladesh. Pp. 23-45. (leftlaborreporter.wordpress.com/2010/)

Shankar, J., \& Famuyiwa, O. O. (1991). Stress among factory workers in a developing country. Journal of Psychosomatic Research, 35, (2-3), 163-171.

Srivastava, A.K., \& Singh, A.P. (1981).Construction and Standardization of an Occupational Stress Index: A pilot study, Indian Journal of Clinical Psychology, 8, 133-136.

Su, S. L., \& Huang, K.L. (1992). Secondary school teachers attitudes towards teachers union participation and strikes (in Chinese), Education and Psychology Research, 15, 173-214.

Sui, A., \& Donald, P. (2011). Workers stress among workers from eight occupational groups in Hong Kong. Journal of Occupational and Environmental, 53, 185-189.

Virtanen, M., Ferrie, J. E., Singh-manoux, A., Shipley, M. J., Vahtera, J., \& Marmot, M. G. (2010). Overtime work and incident coronary heart disease: the Whitehall II prospective cohort study. European Heart Journal, 31, 1737-1744.

Warr, J. G., \& Payne, D. (19983). 'Good jobs' to 'bad jobs': replicated evidence of an employment continuum from two large surveys. Social Science Medicine, 56, 1749-1760.

Wright, I., Bengtsson, C., \& Frankenberg, K. (1994). Aspects of psychological work environment and health among male and female white-collar and blue-collar workers in a big Swedish industry. Journal of organizational Behavior, 15, 177-183.

How to cite this article: B Dey, A Rahman, S Sultana, S sadaf (2016), Garments Worker's Job Stress and Mental Health, International Journal of Indian Psychology, Volume 3, Issue 4, No. 56, ISSN 2348-5396 (e), ISSN: 2349-3429 (p), DIP: 18.01.013/20160304, ISBN: 978-1-365-239922

(c) The International Journal of Indian Psychology, ISSN 2348-5396 (e)| ISSN: 2349-3429 (p) | 136 